\title{
SIMULATION OF FLOW FIELD IN THEORETICAL WATER LIFTING SYSTEM WITH TEMPERATURE DIFFERENCE IN VERTICAL TUBES ON LARGE SCALES
}

\author{
LV, M. - LIU, H. - XIA, M. - WANG, J. - NIE, X. - ZHU, H. - ZHU, Z. \\ School of Mechanical Engineering, Hangzhou Dianzi University \\ Hangzhou Zhejiang 310018, China \\ (phone: +86-0571-86878554; fax: +86-0571-86878604) \\ Corresponding author \\ e-mail: jxliuhaiqiang@hdu.edu.cn; phone:+86-0571-86878554; fax:+86-0571-86878604
}

(Received 28 $8^{\text {th }}$ Apr 2018; accepted 31 $1^{\text {st }}$ Jul 2018)

\begin{abstract}
Lifting water artificially to form an upwelling is considered as a promising way to recover the ocean fishery environment. In order to discuss the feasibility of practical application in theory, the theoretical water lifting system with temperature difference in vertical tubes on large scales was studied by numerical simulation in this paper. Results show that an effective upwelling can be observed in the vertical tube on modeling scales. The characteristic ascending speed varies quite differently for different range of ambient temperature. It is very hard to form an effective upwelling inside the long vertical tube with a big diameter under a very low power and a relative high ambient temperature. In certain cases with fixed tube diameter, the increases of the ambient temperature and the heating power are both favorable for lifting more water from subsurface to the surface. The upwelling in vertical tube benefits from smaller tube diameter under low heating power. But for high heating power, the tube with larger diameter will have better ability to lift more water. In studied cases, a theoretical maximum flow rate of $8.8 \mathrm{~m}^{3} / \mathrm{s}$ could be got for water lifting from the depth of $115 \mathrm{~m}$. Therefore the technology of artificial water lifting via temperature difference is promising for future application.
\end{abstract}

Keywords: artificial upwelling, temperature difference, vertical tube, CFD simulation

\section{Introduction}

Upwelling can bring the nutrient-rich subsurface water to surface, and thus increase phytoplankton production in the euphotic layer. So the upwelling is considered as one of the most important conditions for natural ocean fishing grounds in the world (Williamson et al., 2009; Ryther, 1969). In recent years, the global offshore ecological environment has been worth, and the fishery resources declined (Kirke, 2003). Natural ocean upwelling has seasonal and spatial limitations (Polovina et al., 2001; Yu et al., 2001). Artificial upwelling can make up for those limitations, and play an important role in the marine environment's recovery and the fishery resources' development. In addition, upwelling has been found as a promising way to reduce the accumulation of anthropogenic carbon dioxide in the atmosphere (Pan et al., 2015).

In the past few decades, artificial upwelling technologies have been studied, and many research achievements have been gained. Kazuyuki et al. developed an artificial upwelling device called "Takumi" (Kazuyuki and Alan, 2003; Kazuyuki and Hiroyuki, 1999). The device had a large floating offshore platform. And it used pump for lifting nutrients from deep sea. The prototype of the machine was manufactured and setup at the center of Sagami Bay in Japan. However, the upwelling flow rate was only about $1.2 \mathrm{~m}^{3} / \mathrm{s}$.

Wave pump with check valve was proposed to make artificial upwelling in University of Hawaii (Isaacs et al., 1976; Liu and Jin, 1995; Liu, 1999; White et al., 
2010). The main principle of the wave driving device is that the valve is only open on the down slope of a wave and close on the up slope. An estimated flow rate was about 0.45 to $0.95 \mathrm{~m}^{3} / \mathrm{s}$ for a wave height of $1.90 \mathrm{~m}$ and a wave period of $12 \mathrm{~s}$ (White et al., 2010).

Tsubaki et al. proposed an artificial upwelling system based on the concept "perpetual salt fountain" which is initiated by Stommel et al. (Tsubaki et al., 2007). In many areas of the tropical and subtropical ocean, warm salty water overlies colder fresher water. That causes a famous vertical convective motion calling "salt finger". The salt fingers occur because of the difference in the diffusivities of heat and salt. When a pipe is inserted to connect the deep sea and the surface, the pipe is filled with the low salinity deep sea water, and the salinity of the water inside the pipe is lower than that outside. The upwelled deep sea water becomes almost the same temperature as the surrounding water. Hence buoyancy occurs in the pipe. The upwelling flow can be continues as long as the differences of the temperature and salinity exist. The flow rate with a single pipe was estimated as approximately $45 \mathrm{~m}^{3} /$ day (Hua et al., 2017; Tsubaki et al., 2007).

Taiwan University proposed an air-lift pump for upwelling deep ocean water (Liang and Peng, 2005). For the air-lift pump, air is compressed into a vertical pipe immersed in water. Bubbles ascend and the water level in pipe rises due to the density decrease in the air-water mixture. Once the water level reaches the top of pipe and the water flows out continuously from the lower end (Liang and Peng, 2005). McClimans et al. and Zhejiang University studied the air-lift pump by experiments and CFD simulations, results confirmed effects of the air-lift upwelling system (McClimans et al., 2010; Fan et al., 2013; Qiang et al., 2018; Huang et al., 2017; Yang et al., 2017). Pan and Eranti tried to apply the air bubbler technology in ice control of harbours (Pan and Eranti, 2007; Pan and Eranti, 2009). Tian et al. studied the influence of bubble parameters on the upwelling flow rate (Tian et al., 2014). Leng et al. studied the influence of air-lift artificial upwelling on water temperature (Leng et al., 2014). Zhang et al. discussed the power supply methods for air-lift artificial upwelling systems (Zhang et al., 2016).

Lv et al. proposed an artificial upwelling technology using differential heating method, which was named "Differential-Heating-Liquid-Upwelling" (DHLU) (Lv et al., 2014). This technology is based on the concept "floating raise phenomenon" in natural convection. The vertical temperature gradient in fluid, which is hot at bottom and cold at top, can cause the vertical density gradient inside the fluid. Therefore the inner vertical convection of the fluid occurs for the reason of buoyancy. This technology tries to transfer the solar heat from surface to deep seawater, and heats the deep seawater to make a local warm zone, and then lifts the deep water up to the surface. Several prototypes of this system were invented by Hangzhou Dianzi University (Lv et al., 2015; Lv et al., 2018). In these prototypes, solar energy is absorbed by the working medium in solar collector at water surface, and then the working medium is delivered to the radiator in deep sea through long adiabatic tubes using wave energy or wind energy. The water in deep sea is heated by the radiator and then be lifted to the surface.

The flow field of water lifting system in DHLU is a typical turbulent flow with many quickly ascending masses (Lv et al., 2014). The preliminary study shows that the $k-\varepsilon$ turbulence model is quite suitable for building the numerical model of water lifting system in DHLU (Xia et al., 2016). Studies indicate the feasibility of this technology with bench-scale experiments (Lv et al., 2014). 
In China seas , the nutrient-rich subsurface water usually located at a depth from $20 \mathrm{~m}$ (North China Sea) to a depth deeper than 100m (South China Sea) (Sun, 2006). In order to discuss the feasibility of practical application in China seas in theory, more studies are required for large scale systems with an upwelling height larger than $20 \mathrm{~m}$, even $100 \mathrm{~m}$.

In this paper, we studied the theoretical water lifting system with temperature difference in vertical tubes on large scales by numerical simulation. The flow characteristics of upwelling in big vertical tubes on large scale are studied here. And the influences of several important parameters are discussed.

\section{Numerical settings}

\section{Geometric model and computational grids}

Geometric model was built as Fig. 1 shows. In order to ignore the boundary effects of wall to simulate the real ocean environment, we defined a very big cylindrical water environment for water lifting system. The cylinder's diameter was set as $300 \mathrm{~m}$ and its height was $130 \mathrm{~m}$. The heat source was assumed as a cylindrical heating stick with a diameter of $1 \mathrm{~m}$ and a height of $20 \mathrm{~m}$. The heating stick was located at the bottom center of the cylindrical water environment. The length of vertical tube was set as $100 \mathrm{~m}$. The thickness of the tube wall was ignored. So the tube diameter equals the inner diameter of tube. Two kinds of tube diameters were studied in this paper, $5 \mathrm{~m}$ and $10 \mathrm{~m}$. The top end of the vertical tube was $15 \mathrm{~m}$ below the water surface.

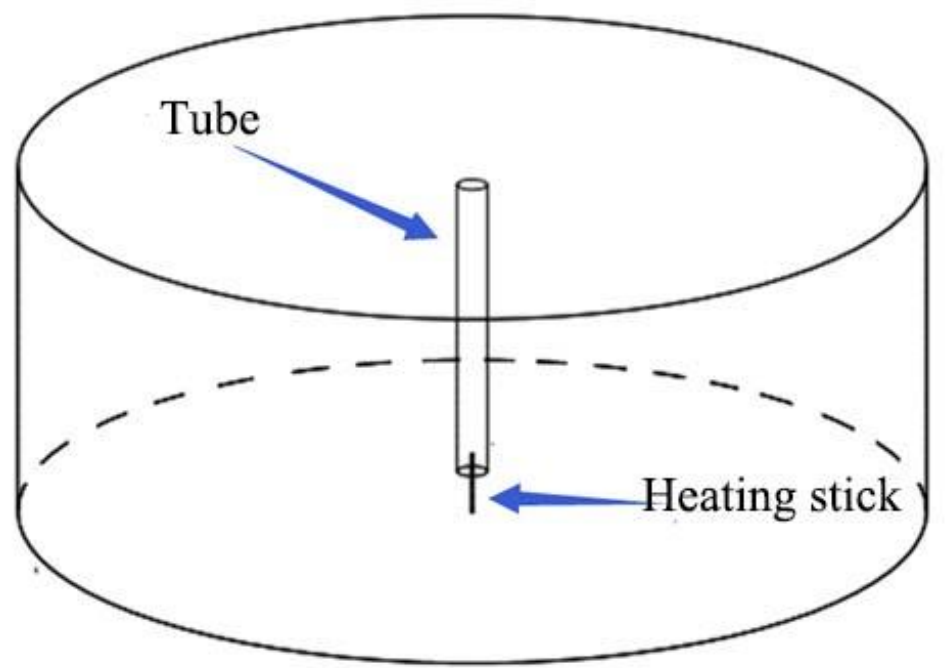

Figure 1. Geometric model

Structured grids were generated by CFD pre-processing software GRIDGEN. The whole 3D grid system of calculation domain is shown in Fig. 2. In order to study the heat transfer process nearby the heat source, grids near the heat source were densified, as Fig. 2 shows. 


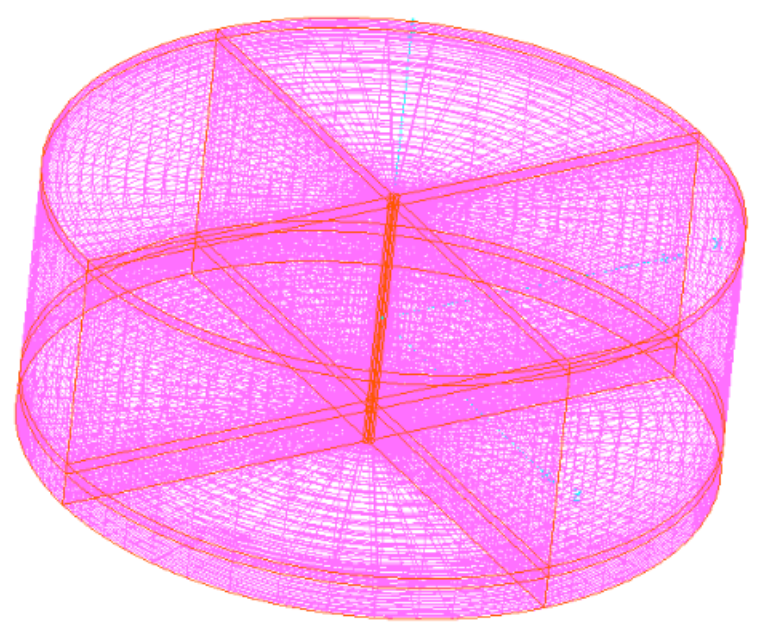

Figure 2. The whole $3 D$ grid system of calculation domain

\section{Numerical model and boundary conditions}

Previous studies showed that the upwelling in DHLU system is a typical turbulent flow (Lv et al., 2014). And the $k-\varepsilon$ turbulence model was proved quite suitable for building the numerical model of water lifting system in DHLU researches (Xia et al., 2016; Ye et al., 2017). So the standard $k-\varepsilon$ turbulence model was chosen for all numerical simulations in this paper. It is one of the most commonly used models in CFD applications for turbulent cases. The FLUENT module of the famous CFD software ANSYS 14.0 was applied in simulations.

In numerical simulation, the material of fluid was chosen as liquid water. The module "piecewise-liner" was used to define the parameters of liquid water at different temperatures, such as density, specific heat, thermal conductivity and viscosity (Xia et al., 2016; Liu et al., 2013).

For boundary conditions, the top surface, bottom surface and the cylindrical surface of water environment were all set as Stationary Wall. And their thermal conditions were all set as with constant temperatures which equal environmental temperature. The boundary conditions of the tube wall and the side surface of the heating stick were all set the same as above. The top surface of the heating stick was also set as Stationary Wall. But its thermal condition was set as with constant heat flux which was decided by the heating power.

\section{Results and Discussion}

The basic characteristics of water lifting system with temperature difference in vertical tubes on large scales were discussed in this paper. And we studied influences of sever important system parameters such as initial temperature, heating power and tube diameter. Two typical ambient temperatures of China sea waters were discussed here: $15^{\circ} \mathrm{C}$ and $25{ }^{\circ} \mathrm{C}$. Considering the energy losses in heat transfer from water surface to heating point, the heating power of heat source was set relatively low in study. Three kinds of heating power were considered here: 100W, $200 \mathrm{~W}$ and $500 \mathrm{~W}$. And two kinds 
of tube diameters were studied in this paper: $5 \mathrm{~m}$ and $10 \mathrm{~m}$. The simulation results were analyzed by the post-processing software TECPLOT, as shown in Fig. 3 and Fig. 4.

\section{Typical flow field of water lifting system}

The typical flow field of water lifting system with temperature differences in vertical tube on large scales is shown in Fig. 3 and Fig. 4. These Fig.s show that there is obvious upwelling in the vertical tube as the reverse temperature gradient exists along the height.

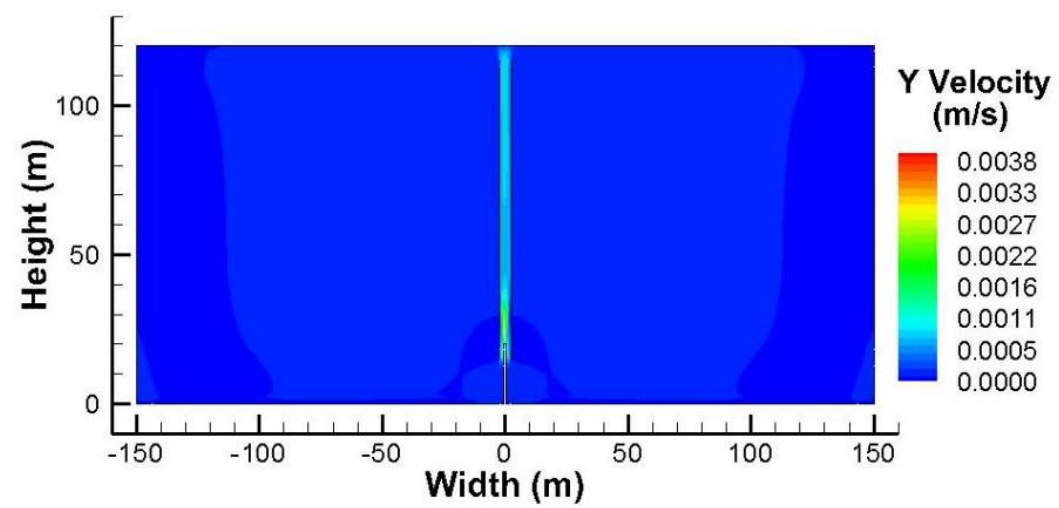

(a) Velocity contour

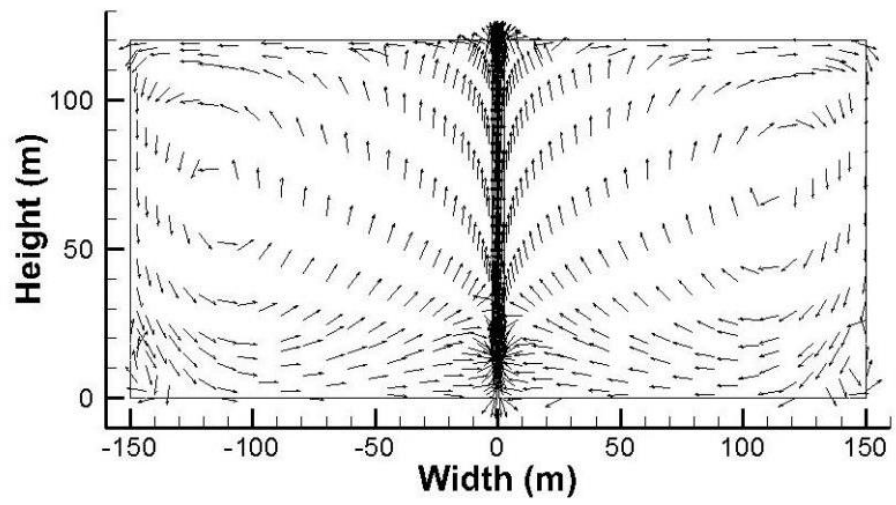

(b) Velocity vector

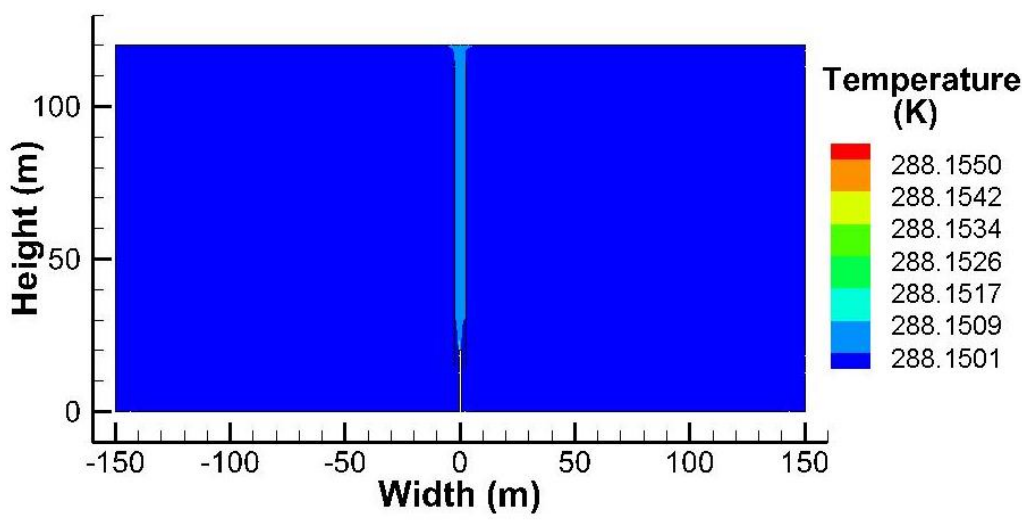

(c) Temperature contour

Figure 3. The flow field of upwelling in a typical case (The initial water temperature is $15^{\circ} \mathrm{C}$, the heating power is $500 \mathrm{~W}$ and the diameter is $5 \mathrm{~m}$ ) 
The upwelling stream fills almost the whole tube. Large vortexes appear around both two end of the tube. Both the velocity field and the temperature field are all with axisymmetric distribution. The largest ascending speed of each horizontal section in upwelling stream appears at the center of tube. Both the velocity gradient and temperature gradient are relative large near the heating surface. But as the height grows, the horizontal temperature distribution in vertical tube becomes uniform much more quickly than the horizontal velocity distribution.

To discuss the flow velocity features of upwelling, we defined a velocity parameterCharacteristic Ascending Speed. The characteristic ascending speed was defined as the ascending speed along the tube axis.It also represented the largest ascending speed at each horizontal section in upwelling.

There was a very small hot region with a height about $1 \mathrm{~m}$ to $3 \mathrm{~m}$ near the heat source, as Fig. 4(b) shows. It was named warm zone here. A relatively large region with higher ascending speed was also observed above the warm zone, as Fig. 4(a) shows. As the temperature gradient was very large there, the buoyancy was large there. Therefore the warm zonewas assumed as the lifting energy storage area which promoted the whole upwelling along the tube.

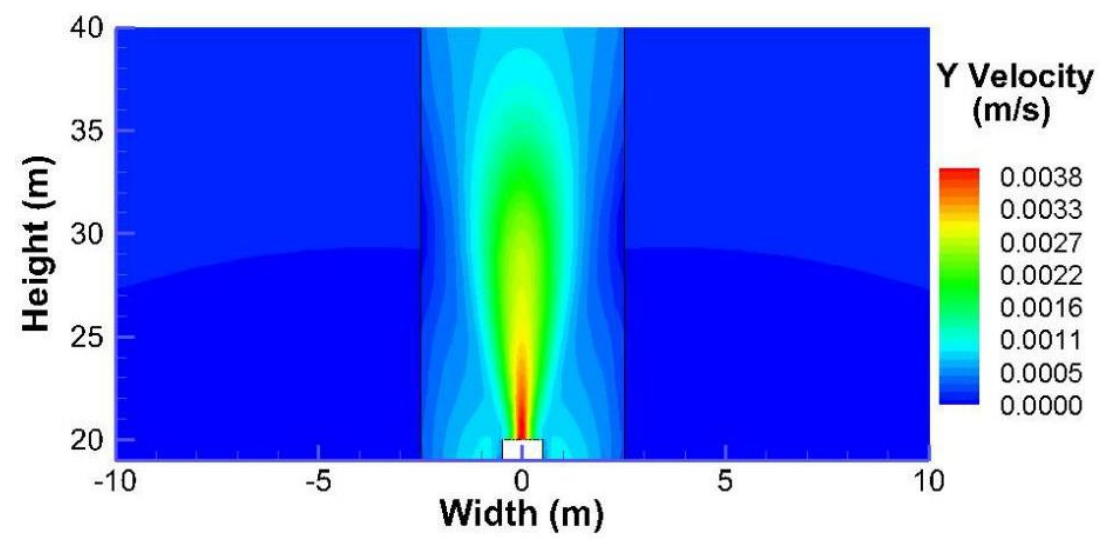

(a) Local velocity contour

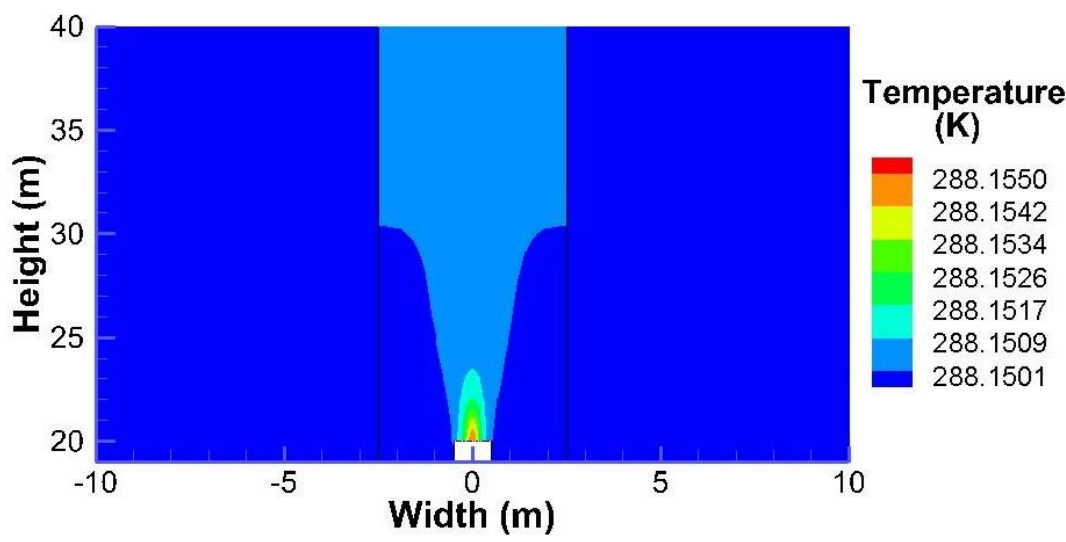

(b) Local temperature contour

Figure 4. The flow field nearing the heat source in typical case (The initial water temperature is $15^{\circ} \mathrm{C}$, the heating power is $500 \mathrm{~W}$ and the diameter is $5 \mathrm{~m}$ ) 


\section{Characteristic ascending speed in upwelling}

The characteristic ascending speeds at different heights in simulated cases are shown in Fig. 5 and Fig. 6.

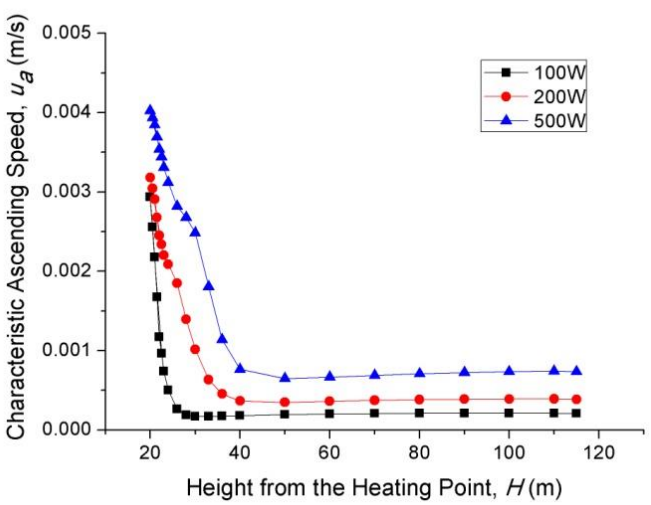

(a) tube diameter is $5 \mathrm{~m}$

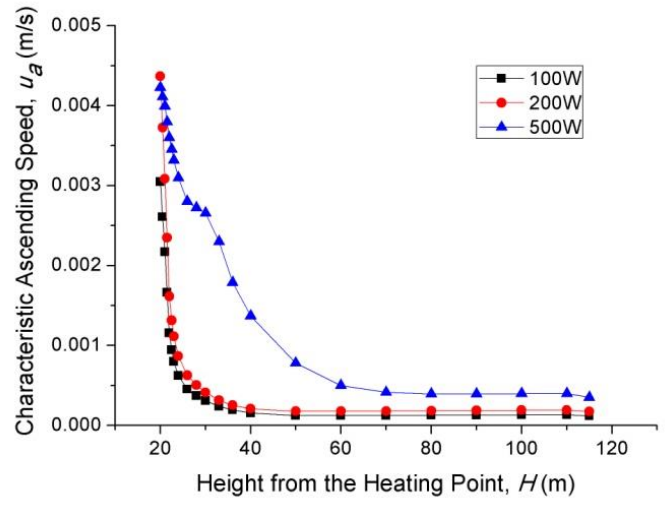

(b) tube diameter is $10 \mathrm{~m}$

Figure 5. Characteristic ascending speeds vs. height for $15^{\circ} \mathrm{C}$ initial water temperatures

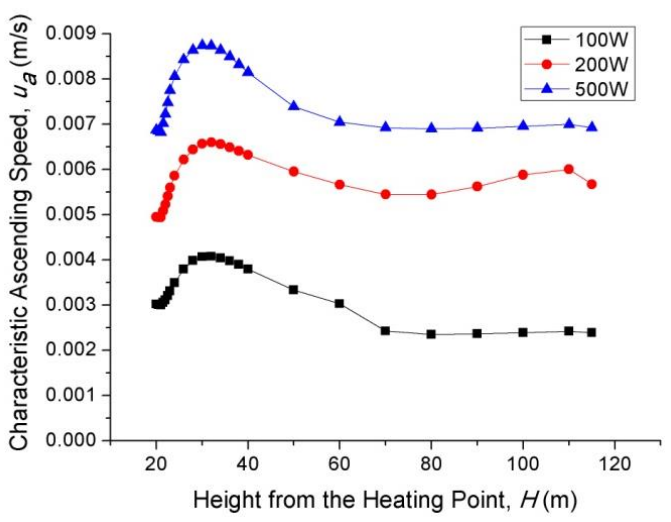

(a) tube diameter is $5 \mathrm{~m}$

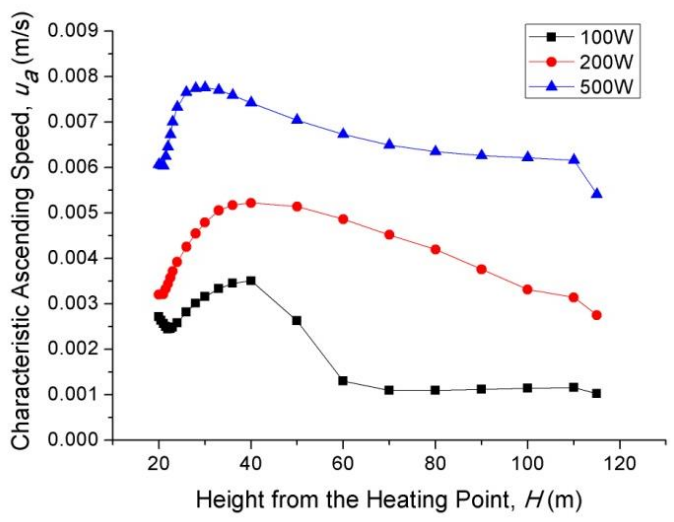

(b) tube diameter is $10 \mathrm{~m}$

Figure 6. Characteristic ascending speeds vs. height for $25^{\circ} \mathrm{C}$ initial water temperatures

Results show that under a lower initial water temperature of $15^{\circ} \mathrm{C}$, the characteristic ascending speed drops very quickly as the height increases from zero. When the height increases to a certain value, the drop rate of the characteristic ascending speed becomes slow. And finally the characteristic ascending speed increases very slowly as the height increases while near the outlet of tube, as Fig. 5 shows. In studied cases, the smallest values of the characteristic ascending speed for different heating powers all appear at a height scale of $30 \mathrm{~m}-70 \mathrm{~m}$. In certain case with a given $15{ }^{\circ} \mathrm{C}$ initial temperature, the smallest value of the characteristic ascending speed and the height where it appears are both relatively small for smaller heating power. While other parameters keep the same, the larger the tube diameter is, the larger the smallest value of the characteristic ascending speed becomes, and the higher the height reaches where the smallest value appears. With a fixed tube diameter and a certain height, the characteristic ascending 
speed increases as the heating power increases under the $15{ }^{\circ} \mathrm{C}$ initial water temperature.With a fixed tube diameter,the dropping rate of the characteristic ascending speed in deceleration area increases as the heating power decreases.

Under a higher initial water temperature of $25^{\circ} \mathrm{C}$, the characteristic ascending speed decreases a little while the height increases from the heating point. And then as the height keeps increasing, the characteristic ascending speed increases first and decreases later as the height increases. Finally, the characteristic ascending speed keeps relative uniform while near the water surface. In all studied cases with the $25{ }^{\circ} \mathrm{C}$ initial water temperature, the maximum values of the characteristic ascending speed appear at a height scale of $30 \mathrm{~m}-40 \mathrm{~m}$. While the heating power increases, the maximum value of the characteristic ascending speed increases, and the height where it appears decreases. In certain cases with a fixed heating power, the smaller the tube diameter is, the larger the maximum value of characteristic ascending speed reaches, and the lower the height is where the maximum value appears. While the initial water temperature is $25^{\circ} \mathrm{C}$, the maximum value of characteristic ascending speed appears in the case with a tube diameter of $5 \mathrm{~m}$ and a heating power of $500 \mathrm{~W}$.

Overall, on sight of the ascending speed, the upwelling seems more effective with a higher heating power, a higher initial water temperature and a smaller tube diameter.

\section{Flow rate of the lifted water in tube}

According to the continuity equations, flow rate of each cross section in tube keeps the same value. So the flow rate of the lifted water in tube could be counted at the outlet cross section of tube. It was calculated as follows:

$$
Q=\sum_{A_{E}} v_{i} \mathrm{~d} A_{i}
$$

The simulation results of upwelling's flow rate for studied cases are shown in Fig. 7 and Fig. 8 .

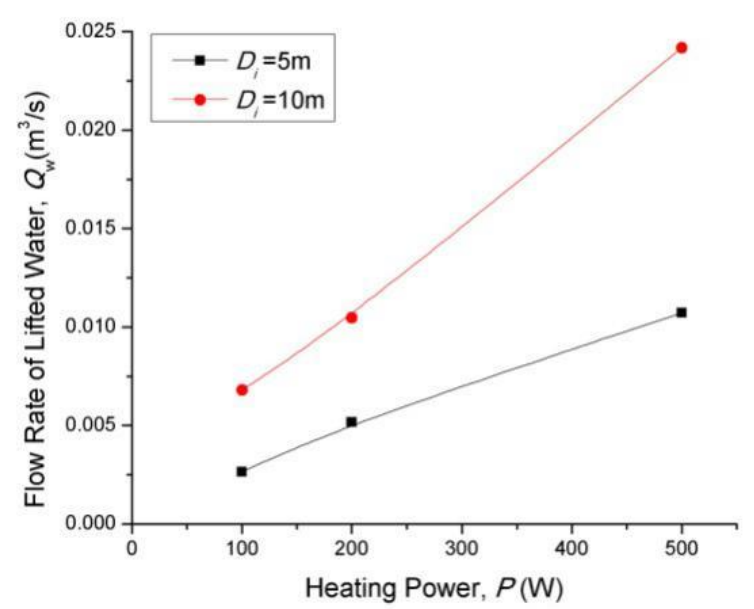

Figure 7. The flow rate of lifted water vs. height for different heating powers under $15{ }^{\circ} \mathrm{C}$ initial water temperature 


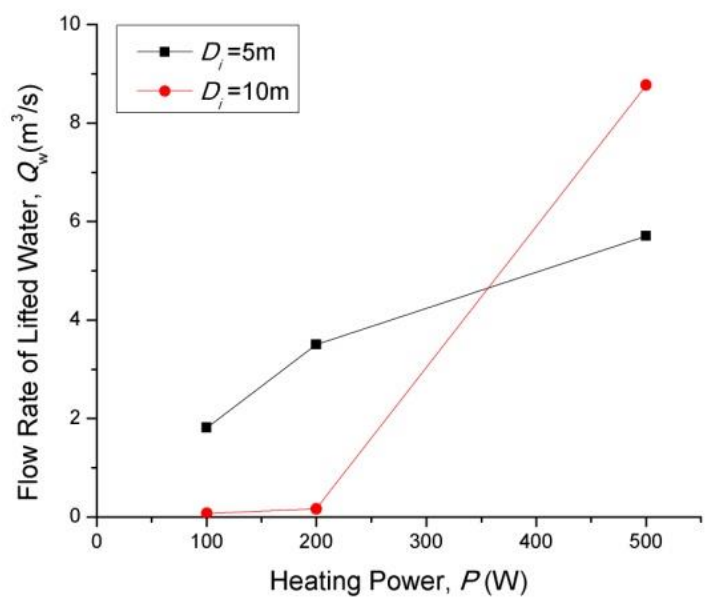

Figure 8. The flow rate of lifted water vs. height for different heating powers under $25{ }^{\circ} \mathrm{C}$ initial water temperature

As Fig. 7 and Fig. 8 show, in certain cases with a fixed initial temperature and the same tube diameter, the flow rate of lifted water increases as the heating power increases. As the initial water temperature increases, the increasing rate of the flow rate increases. Generally speaking in certain cases with a fixed heating power and the same tube diameter, the flow rate of lifted water increases as the initial water temperature increases. But it should be noticed that while the heating power is relatively low (100W and $200 \mathrm{~W})$ and the tube diameter is relatively large $(10 \mathrm{~m})$, the flow rate at a higher initial water temperature $\left(25^{\circ} \mathrm{C}\right)$ is smaller than that under $15^{\circ} \mathrm{C}$. While the initial water temperature is relative high and the heating power is very small $(100 \mathrm{~W})$, the flow rate of lifted water is larger for tube with a smaller diameter. Under the $15^{\circ} \mathrm{C}$ initial water temperature, the tube with a larger diameter $(10 \mathrm{~m})$ has a larger flow rate than the tube with a smaller diameter $(5 \mathrm{~m})$. Under the $25{ }^{\circ} \mathrm{C}$ initial water temperature, the increasing rate of flow rate to heating power is larger for tube with bigger diameter.

Overall, the simulation results indicated that it is very hard to form an effective upwelling inside a long vertical tube with a big diameter and a low heating power, while the ambient temperature is relatively high. In certain cases with a fixed tube diameter, the increases of the ambient temperature and the heating power are advantageous to lifting more water from deep sea to the surface. While under low heating power, upwelling in vertical tube benefits from smaller tube diameter. But for high heating power, the tube with larger diameter will have better ability to lift more water. In studied cases, a theoretical maximum flow rate of $8.8 \mathrm{~m}^{3} / \mathrm{s}$ was got for water lifting on large scales.

\section{Conclusions}

The theoretical water lifting system with temperature difference in vertical tubes on large scales was studied by numerical simulations in this paper. Results show that an effective upwelling can be observed in the vertical tube on studied scale. For the tube with a smaller diameter or the heat source with a higher heating power, the upwelling 
stream fills almost the whole tube. The characteristic ascending speed drops very quickly at first and then increases to a certain value as the height increases for a lower ambient temperature. But for a higher ambient temperature, the characteristic ascending speed increases first and then decreases as the height increases.

Results also indicate that it is very hard to form an effective upwelling inside a long vertical tube with a big diameter and a low heating power, while the ambient temperature is relatively high. In certain cases with fixed tube diameter, the increases of the ambient temperature and the heating power are beneficial for lifting more water from subsurface to the surface. The upwelling in vertical tube gains benefit from smaller tube diameter while under a relatively low heating power. However for the high heating power, the tube with larger diameter will have better ability to lift more water. In studied cases, a theoretical maximum flow rate of $8.8 \mathrm{~m}^{3} / \mathrm{s}$ was got for water lifting from the depth of $115 \mathrm{~m}$. Therefore the technology of artificial water lifting via temperature difference is promising for future application.

Acknowledgements. Authors wish to acknowledge the sponsor of the Zhejiang Provincial Natural Science Foundation (No. LY16E090006), the National Natural Science Foundation of China (No.51209062, No.51506042, No.11472095), the Zhejiang Provincial Science and Technology Project (No.2018C04002).

\section{REFERENCES}

[1] Fan, W., Pan, Y., Zhang, D., Xu, C., Qiang, Y., Chen, Y. (2016): Experimental study on the performance of a wave pump for artificial upwelling. - Ocean Engineering 113: 191200.

[2] Fan, W., Chen, J., Pan, Y., Huang, H., Chen, C. T. A., Chen, Y. (2013): Experimental study on the performance of an air-lift pump for artificial upwelling. - Ocean Engineering 59: 47-57.

[3] Hua, D., Yan, L., Yingchao, Z., Hou, Z., Peipei, C., Jia, W., Ashraf, M. A. (2017): Prediction of Hub Height Winds over the Plateau Terrain by using WRF /YSU/Noah and Statistical Forecast. - Earth Science Research Journal 21(1): 37-43.

[4] Huang, H., Wu, J., Yang, Z., Xue, Z., Ge, W., Wei, Y., Fan, W., Chen, J., Chen, Y. (2017): A CFD simulation study of air-lift artificial upwelling based on Qiandao Lake experiment. - Ocean Engineering 144: 257-265.

[5] Isaacs, J. D., Castel, D., Wick, G. L. (1976): Utilization of the energy in ocean waves. Ocean Engineering 3: 175-187.

[6] Kazuyuki, O., Alan, J. M. (2003): Real sea experiment of ocean nutrient enhancer "TAKUMI" upwelling deep ocean water. - Oceans Proceedings: 881-885.

[7] Kazuyuki, O., Hiroyuki, N. (1999): The deep ocean water upwelling machine using density current-Creation of fishing ground and absorption of CO2. - Oceans'99 MTS/IEEE 2: 1019-1024.

[8] Kirke, B. (2003): Enhancing fish stocks with wave-powered artificial upwelling. - Ocean \& Coastal Management 46: 901-915.

[9] Leng, J., Huang, H., Chen, J., Fan, W., Han, G., Shan, L., Liu, M., Yang, J., Chen, Y. (2014): Influence of air-lift artificial upwelling on water temperature. - Journal of Mechanical \& Electrical Engineering (04): 442-445.

[10] Liang, N. K., Peng, H. K. (2005): A study of air-lift artificial upwelling. - Ocean Engineering 32: 731-745.

[11] Liu, C.(1999): Research on artificial upwelling and mixing at the University of Hawaii at Manoa. - IOA Newsletter 10(4): 1-8. 
[12] Liu, C. C. K., Jin, Q. (1995): Artificial upwelling in regular and random waves. - Ocean Engineering 22(4): 337-350.

[13] Liu, G., Ma, L., Xiang, S. (2013): Chemistry and Chemical Properties Datasheet Inorganic volume. - Beijing: Chemical Industry Press: 3-23.

[14] Lv, M., Liu, H., Nie, X., Pan, H. (2015): A device and method of water lifting via temperature differences using solar energy. - Chinese Invention Patent: 201410085437.X.

[15] Lv, M., Xia, M., Nie, X., Pan, H., Liu, H., Zhou, Z. (2018): A device and method of seabed nutrients lifting system using wind energy. - Chinese Invention Patent: 201510711713.3.

[16] Lv, M., Yan, X., Nie, X., Pan, H., Liu, H. (2014): Experimental studies of differential heating for artificial upwelling. - Computer Modelling and New Technologies26(6): 299303.

[17] McClimans, T. A., Handa, A., Fredheim, A., Lien, E., Reitan, K. I. (2010): Controlled artificial upwelling in a fjord to stimulate non-toxic algae. - Aquacultural Engineering 42: 140-147.

[18] Pan, H., Eranti, E. (2007): Applicability of air bubbler lines for ice control in harbours. China Ocean Engineering 21(2): 215-224.

[19] Pan, H., Eranti, E. (2009): Flow and heat transfer simulations for the design of the Helsinki Vuosaari harbour ice. - Cold Regions Science and Technology 55: 304-310.

[20] Pan, Y., Fan, W., Huang, T, Wang, S., Chen, C. T. A. (2015): Evaluation of the sinks and sources of 564 atmospheric $\mathrm{CO} 2$ by artificial upwelling. - The Science of the Total Environment 511: 692-702.

[21] Polovina, J. J., Howell, E., Kobayashi, D. R., Seki, M. P. (2001): The transition zone chlorophyll front, a dynamic global feature defining migration and forage habitat for marine resources. - Progress in Oceanography 49(3): 469-483.

[22] Qiang, Y., Fan, W., Xiao, C., Pan, Y., Chen, Y. (2018): Effects of operating parameters and injection method on the performance of an artificial upwelling by using airlift pump. - Applied Ocean Research 78: 212-222.

[23] Ryther, J. H. (1969): Photosysthesis and fish production in the sea. - Science 166: 72-76.

[24] Sun, X. (2006): Offshore regional seas in China. - Beijing: Ocean Press: 238-248.

[25] Tian, X., Pan, H., Zhang, H., Zheng, Y. (2014): Experimental study of the influence of the bubble size on the upwelling flow rate. - Chinese Journal of Hydrodynamics (05): 586-591.

[26] Tsubaki, K., Maruyama, S., Komiya, A., Mitsugashira, H. (2007): Continuous measurement of an water induced by the perpetual salt fountain artificial upwelling of deep sea. - Deep-Sea Research I, 54: 75-84.

[27] White, A., Björkman, K., Grabowski, E., Letelier, R., Poulos, S., Watkins, B., Karl, D. (2010): An open ocean trial of controlled upwelling using wave pump technology. Journal of Atmospheric and Oceanic Technology 27: 385-396.

[28] Williamson, N., Komiya, A., Maruyama, S., Behnia, M., Armfield, S. W. (2009): Nutrient transport from an artificial upwelling of deep sea water. - Journal of Oceanography 65: 349-359.

[29] Xia, M., Lv, M., Pan, H. (2016): The Numerical Simulations of Differential Heating Liquid Upwelling. - Journal of Hangzhou Dianzi University (Natural Science) 36(6): 5056.

[30] Yang, J., Zhang, D., Chen, Y., Fan, W., Liang, H., Tan, M. (2017): Feasibility analysis and trial of air-lift artificial upwelling powered by hybrid energy system. - Ocean Engineering 129: 520-528.

[31] Ye, Y. Y., Luo, Y., Wang, Y., Lin, M., Xiang, P., Ashraf, M. A. (2017): Relation between diversity of phytolankton and environmental factors in waters around Nanri island. Applied Ecology \& Environmental Research 15(3): 241-252. 
[32] Yu, Z. G., Mi, T. Z., Yao, Q. Z., Xie, B. D., Zhang, J. (2001): Nutrients concentration and changes in decade-scale in the central Bohai Sea. - Acta Oceanologica Sinica 20(1): 6571.

[33] Zhang, D., Fan, W., Yang, J., Pan, Y., Chen, Y., Huang, H., Chen, J. (2016): Reviews of power supply and environmental energy conversions for artificial upwelling. Renewable and Sustainable Energy Reviews 56: 659-668. 